\title{
HUBUNGAN KECERDASAN SOSIAL DENGAN KESEPIAN PADA REMAJA
}

\author{
Garvin \\ Fakultas Psikologi, Universitas Bunda Mulia \\ Email: garvin.goei@gmail.com
}

\begin{abstract}
ABSTRAK
Penelitian ini bermaksud untuk meneliti hubungan antara kecerdasan sosial dan kesepian pada remaja. Diketahui bahwa remaja mudah mengalami kesepian sebagai akibat dari proses perkembangan secara fisik, kognitif, maupun psikososial. Kesepian memiliki dampak yang negatif baik untuk perkembangan serta kesehatan mental remaja seperti perilaku delinkuen, depresi, hingga kecanduan dengan permainan online; sehingga perlu mendapatkan perhatian dan penanganan. Penelitian sebelumnya menunjukkan bahwa salah satu penyebab remaja mengalami kesepian adalah perasaan tidak diterima, tidak dipahami, dan kesulitan dalam berinteraksi secara sosial (Bruno dalam Tiska, 2012). Remaja dengan harga diri yang rendah juga rentan mengalami kesepian (Nurmina, 2008), sedangkan dalam penelitian sebelumnya diketahui bahwa kecerdasan sosial berhubungan secara positif dengan harga diri (Alfiasari, Latifah, dan Wulandari, 2011). Penelitian ini melibatkan 165 partisipan yang berada pada rentang remaja dan berdomisili di Jakarta, dengan teknik pengambilan sampel menggunakan purposive sampling. Instrumen yang digunakan dalam penelitian ini adalah Tromso Social Intelligence Scale dan UCLA Loneliness Scale versi 3. Hasil uji korelasi Spearman menunjukkan terdapat hubungan yang signifikan antara kecerdasan sosial dengan kesepian pada remaja $\left(r_{s}=-0,332, p=0,000\right)$. Simpulan dari penelitian ini adalah semakin tinggi kecerdasan sosial pada remaja, maka akan semakin rendah kesepian yang dialami oleh remaja, demikian pula dengan sebaliknya. Peneliti kemudian menyarankan agar orangtua maupun pendidik juga perlu memerhatikan dan melatih kecerdasan sosial remaja agar tidak mudah mengalami kesepian.
\end{abstract}

Kata kunci: Kecerdasan sosial, kesepian, remaja

\section{PENDAHULUAN}

\section{Latar Belakang}

Masa remaja merupakan masa peralihan antara anak-anak menuju dewasa, yang digambarkan sebagai masa penuh dengan storm and stress atau badai dan tekanan. Pada masa ini, remaja mengalami perubahan dunia sosial yang begitu cepat dan drastis (Laursen dan Hartl, 2013). Misalnya, individu yang sudah beranjak remaja akan mulai mencari jarak antara ia dengan orangtuanya, dengan tujuan untuk memeroleh independensi dari pengawasan orangtua (Smetana, 1996). Hal ini terjadi karena remaja sangat mengharapkan kebebasan, namun proses ini seringkali membawa masalah pada diri remaja sebab keinginan untuk independen tersebut tidak diseimbangi dengan hubungan yang erat dengan pihak lain, sehingga remaja pun mengalami perasaan terisolasi secara sosial (Reis \& Buhl, 2008). Perasaan terisolasi tersebut kemudian menimbulkan rasa kesepian pada remaja. Baron dan Byrne (2005) menyatakan bahwa kesepian merupakan hal yang sering dialami oleh remaja. Menurut Laursen dan Hartl (2013), perubahanperubahan yang terjadi selama masa perkembangan remaja dapat meningkatkan risiko kesepian pada individu.

Weiss (dalam Gultom, 2015) mendefinisikan kesepian sebagai suatu kondisi emosi yang negatif dan seseorang bisa saja merasa kesepian meski berada di tengah kerumunan atau keramaian sekalipun. Perlman dan Peplau (dalam Agusti \& Leonardi, 2015) membagi kesepian menjadi dua macam, yakni: (1) kesepian emosional, yakni kesepian yang terjadi karena tidak adanya hubungan yang intim dengan orang lain, dan (2) kesepian sosial, ketika seseorang tidak memiliki rasa keterlibatan di dalam masyarakat. Meskipun berbeda, kedua macam kesepian tersebut 
memiliki relasi dengan orang lain, yang berarti kesepian yang dialami oleh seseorang memiliki kaitan dengan hubungan sosialnya dengan orang lain.

Meski sering dialami oleh remaja, kesepian memiliki dampak yang kurang positif terhadap kesehatan psikologis remaja (Corsano, 2006; Gultom, 2015). Hardie (2007) menemukan bahwa orang-orang yang mengalami kesepian secara emosional cenderung mengalami kecanduan internet. Penelitian yang dilakukan di Indonesia (Agusti \& Leonardi, 2015) pun menemukan hal yang serupa, bahwa rasa kesepian pada remaja memiliki korelasi dengan penggunaan internet yang tidak sesuai. Penelitian yang dilakukan oleh Tiska (2012) di Indonesia menemukan bahwa remaja yang senang melakukan clubbing memiliki rasa kesepian yang tinggi. Mereka melakukan clubbing karena ada rasa kesepian dan ingin mencari perhatian maupun afeksi dari orang lain, sehingga mereka mencarinya di tempat yang tidak sesuai yakni tempat hiburan malam. Remaja yang mengalami kesepian juga rentan dengan bunuh diri (Page, 2006). Selain itu, remaja yang gagal membentuk persahabatan yang akrab akan mengalami penurunan harga diri (Santrock, 2005). Hasil penelitian juga menunjukkan bahwa rasa kesepian secara sosial dapat meningkatkan kemungkinan remaja untuk menjadi korban perundungan (Acquah, Topalli, Wilson, Junttila, \& Niemi, 2016).

Berdasarkan hal-hal tersebut, maka penelusuran mengenai prediktor kesepian pada remaja merupakan hal yang penting. Penelitian sebelumnya menunjukkan bahwa persepsi penerimaan teman sebaya dapat menurunkan kesepian yang dialami oleh remaja (Triani, 2012). Faktor individual seperti self-esteem (Nurmina, 2008; Zhao, Kong, \& Wang, 2012) dan shyness (Vanhalst, Luyckx, \& Goossens; 2014) diketahui berhubungan langsung dengan kesepian pada remaja. Selain itu, pengalaman bersama teman sebaya seperti penerimaan yang negatif, kualitas hubungan yang kurang, atau bahkan kurangnya pertemanan juga dapat menimbulkan kesepian pada remaja (Vanhalst et al, 2014). Lebih lanjut lagi, Bruno (dalam Tiska, 2012) menyatakan bahwa orang yang kesepian juga merasa tidak dicintai, ditolak dan merasa tidak dimengerti, dan sulit membuka diri dan menutup atau tertutup. Mahon, Yarcheski, Yarcheski, Cannella, dan Hanks (2006) juga menambahkan bahwa dukungan sosial memiliki pengaruh yang cukup besar terhadap kesepian remaja.

Berdasarkan berbagai penelitian sebelumnya terkait dengan prediktor maupun anteseden dari kesepian remaja, maka dapat disimpulkan bahwa relasi remaja dengan sebayanya sangat berperan terhadap kesepian remaja. Kemampuan seseorang dalam berkomunikasi dan berelasi dengan orang lain disebut juga sebagai kecerdasan sosial. Kecerdasan sosial sendiri terdiri dari tiga faktor, yakni: keterampilan sosial, pemrosesan informasi sosial, dan kesadaran sosial (Silvera, Martinus, \& Dahl; 2001). Remaja dengan kecerdasan sosial yang tinggi juga seharusnya mampu memahami dan menghadapi orang-orang yang berada di sekitarnya (Goleman, 2006) sehingga tidak mudah untuk mengalami pengasingan ataupun merasa ditolak oleh orang lain. Selain itu, kecerdasan sosial juga diketahui berhubungan secara positif dengan harga diri (Alfiasari, Latifah, \& Wulandari, 2011), di mana harga diri merupakan salah satu prediktor dari kesepian remaja (Zhao, Kong, \& Wang; 2012). Atas pertimbangan-pertimbangan tersebut, peneliti melakukan penelitian yang berjudul "hubungan kecerdasan sosial dengan kesepian pada remaja".

\section{Rumusan Masalah}

Berdasarkan identifikasi masalah yang telah dilakukan, maka rumusan masalah dalam penelitian ini adalah apakah terdapat hubungan antara kecerdasan sosial dengan kesepian pada remaja? 


\section{METODE PENELITIAN}

\section{Partisipan penelitian}

Partisipan yang terlibat dalam penelitian ini adalah remaja yang duduk di bangku SMA maupun SMK di Jakarta. Peneliti tidak membatasi suku bangsa dan jenis kelamin dalam menentukan partisipan penelitian. Partisipan dalam penelitian ini berjumlah 165 orang dengan teknik pengambilan sampel menggunakan purposive sampling.

\section{Instrumen penelitian}

Instrumen yang digunakan dalam penelitian ini adalah Tromso Social Intelligence Scale sosial dan UCLA Loneliness Scale veri ketiga. Tromso Social Intelligence Scale terdiri dari 21 butir, digunakan untuk mengukur kecerdasan sosial. Alat ukur ini disusun oleh Silvera, Martinussen, dan Dahl (2001) serta diketahui memiliki validitas dan reliabilitas yang baik. Tromso Social Intelligence Scale berisikan pernyataan-pernyataan terkait dengan diri sendiri yang harus dijawab oleh partisipan. Partisipan harus menilai pernyataan-pernyataan tersebut dengan pilihan penilaian dimulai dari skor 1 yang berarti "sangat tidak menggambarkan diri saya" hingga skor 7 yang berarti "sangat menggambarkan diri saya". Peneliti kemudian menerjemahkan alat ukur tersebut ke dalam Bahasa Indonesia dan melakukan uji coba. Berdasarkan hasil uji coba, alat ukur yang dipertahankan dalam adaptasi Tromso Social Intelligence Scale adalah 15 butir dengan skor Cronbach's Alpha sebesar 0,78; yang mengindikasikan alat ukur ini tergolong reliabel.

Selain itu, UCLA Loneliness Scale digunakan untuk mengukur kesepian. Keunggulan dari alat ukur ini adalah tidak ada satupun butir yang menggunakan kata "kesepian" sehingga partisipan tidak akan mengetahui konstruk yang sedang diukur ketika mengisi skala tersebut. Alat ukur ini memiliki validitas dan reliabilitas yang adekuat (Russell, 1996) serta umum digunakan dalam penelitian-penelitian mengenai kesepian. UCLA Loneliness Scale terdiri dari 20 butir yang berisikan pertanyaan-pertanyaan yang harus dijawab oleh pengisi skala dengan pilihan "tidak pernah", "jarang", "kadang-kadang", dan "sering". Peneliti kemudian menerjemahkan alat ukur tersebut ke dalam Bahasa Indonesia dan diujicobakan, jumlah butir yang dipertahankan dalam adaptasi UCLA Loneliness Scale adalah 19 butir dan menghasilkan skor Cronbach's Alpha sebesar 0,747 .

\section{Teknik pengolahan data}

Peneliti melakukan analisis data statistik dengan menggunakan uji korelasi Spearman untuk mengetahui hubungan antara kecerdasan sosial dan kesepian pada remaja.

\section{HASIL DAN PEMBAHASAN}

\section{Gambaran umum partisipan penelitian berdasarkan jenis kelamin}

Penelitian ini melibatkan 165 partisipan, dengan 83 di antaranya berjenis kelamin laki-laki dan 82 di antaranya berjenis kelamin perempuan. 
Tabel 1. Gambaran umum berdasarkan jenis kelamin

\begin{tabular}{ccc}
\hline Jenis kelamin & Frekuensi (orang) & Persentase \\
\hline Laki-Laki & 83 & 50,3 \\
Perempuan & 82 & 49,7 \\
\hline Total & 165 & 100 \\
\hline
\end{tabular}

\section{Gambaran umum partisipan penelitian berdasarkan usia}

Rentang usia partisipan dalam penelitian ini berkisar antara 14 sampai 18 tahun. Usia dengan frekuensi terbanyak adalah usia 16 tahun dengan frekuensi sebesar 85 orang atau 51,5\% dari total partisipan; sedangkan usia dengan frekuensi terendah adalah partisipan berusia 14 tahun dengan frekuensi sebesar 1 orang atau 0,6\% dari total partisipan.

Tabel 2. Gambaran umum berdasarkan usia

\begin{tabular}{ccc}
\hline Usia (tahun) & Frekuensi (orang) & Persentase \\
\hline 14 & 1 & 0,6 \\
15 & 7 & 4,2 \\
16 & 85 & 51,5 \\
17 & 62 & 37,6 \\
18 & 10 & 6,1 \\
\hline Total & $\mathbf{1 6 5}$ & $\mathbf{1 0 0}$ \\
\hline
\end{tabular}

\section{Gambaran umum kecerdasan sosial dan kesepian pada partisipan penelitian}

Berdasarkan data yang diperoleh, skor rata-rata dan simpangan baku pada variabel kecerdasan sosial secara berturut-turut adalah $\mathrm{M}=40,424$ dan $\mathrm{s}=5,447$. Adapun skor minimal dan maksimal yang diperoleh adalah $\min =23$ dan $\max =55$. Selain itu, skor rata-rata dan simpangan baku kesepian pada partisipan penelitian secara berturut-turut adalah $\mathrm{M}=39,618$ dan $\mathrm{s}=8,002$. Adapun skor minimal dan maksimalnya adalah $\min =23$ dan $\max =65$.

Tabel 3. Gambaran umum skor kecerdasan sosial dan kesepian

\begin{tabular}{ccccc}
\hline Variabel & Rata-Rata & $\begin{array}{c}\text { Simpangan } \\
\text { Baku }\end{array}$ & $\begin{array}{c}\text { Skor } \\
\text { Minimum }\end{array}$ & Skor Maksimum \\
\hline Kecerdasan Sosial & 40,424 & 5,447 & 23 & 55 \\
Kesepian & 39,618 & 8,002 & 23 & 65 \\
\hline
\end{tabular}

\section{Uji normalitas variabel kecerdasan sosial dan kesepian}

Sebelum uji korelasi dilakukan, maka peneliti melakukan uji asumsi terlebih dahulu. Uji asumsi yang digunakan sebelum melakukan uji korelasi adalah uji normalitas. Tujuan dari uji normalitas adalah untuk melihat apakah data terdistribusi dengan normal. Normal atau tidaknya data berpengaruh terhadap uji korelasi yang digunakan. Bila data terdistribusi normal, maka uji korelasi yang dilakukan adalah parametrik atau uji korelasi Pearson; namun bila data tidak 
terdistribusi dengan normal, uji korelasi yang dilakukan adalah non-parametrik atau uji korelasi Spearman.

Berdasarkan hasil uji normalitas yang menggunakan uji Kolmogorov-Smirnov, diketahui bahwa skor $p$ pada variabel kesepian lebih kecil dari $0,05(p=0,012<0,05)$ yang menandakan bahwa data terdistribusi dengan tidak normal; sedangkan skor $p$ pada variabel kecerdasan sosial juga lebih kecil dari 0,05 $(p=0,024<0,05)$ yang berarti data juga tidak terdistribusi dengan normal. Oleh sebab itu, maka uji korelasi yang akan dilakukan adalah korelasi non-parametrik dengan menggunakan uji Spearman.

Tabel 4. Hasil uji normalitas kedua variabel

\begin{tabular}{ccc}
\hline Variabel & $p$ & Interpretasi \\
\hline Kecerdasan sosial & 0,024 & Data tidak terdistribusi secara normal \\
Kesepian & 0,012 & Data tidak terdistribusi secara normal \\
\hline
\end{tabular}

\section{Uji korelasi variabel kecerdasan sosial dan kesepian}

Penelitian ini bermaksud untuk melihat hubungan antara kecerdasan sosial dan kesepian pada remaja, oleh karena itu peneliti melakukan uji korelasi untuk melihat hubungan di antara kedua variabel tersebut. Hasil uji korelasi Spearman menunjukkan hasil bahwa terdapat hubungan yang signifikan antara kecerdasan sosial dan kesepian, dan korelasi tersebut bersifat negatif $\left(\mathrm{r}_{\mathrm{s}}=-\right.$ $0,332 ; p=0,000<0,05)$. Berarti, semakin tinggi skor kecerdasan sosial, akan semakin rendah skor kesepian; begitu pula dengan sebaliknya.

Hal ini sejalan dengan penelitian yang dilakukan oleh Alfiasari, Latifah, dan Wulandari (2011) yang menunjukkan bahwa kecerdasan sosial berhubungan secara positif dengan harga diri, serta harga diri berhubungan secara negatif dengan kesepian (Nurmina, 2008). Hal ini juga sejalan dengan Burno (dalam Tiska, 2012) yang menyatakan bahwa orang yang kesepian adalah orang yang sulit membuka diri terhadap orang lain, sedangkan Goleman (2006) menyatakan bahwa individu yang memiliki kecerdasan sosial tinggi mampu untuk memahami dan menghadapi orang-orang di sekitarnya.

\section{KESIMPULAN DAN SARAN}

Berdasarkan hasil penelitian, peneliti menyimpulkan bahwa terdapat hubungan yang negatif antara kecerdasan sosial dan kesepian pada remaja. Remaja yang tinggi dalam kecerdasan sosial akan cenderung memiliki tingkat kesepian yang lebih rendah; dan sebaliknya, remaja yang tergolong kurang dalam kecerdasan sosial akan cenderung lebih tinggi dalam merasakan kesepian. Hal ini selaras dengan Vanhalst, Luycks, dan Goossens (2014) yang menyatakan bahwa pengalaman bersama teman sebaya dan kualitas hubungan pertemanan pada remaja berhubungan dengan kesepian pada remaja. Temuan penelitian ini juga sesuai dengan penelitian sebelumnya yang menyatakan bahwa kecerdasan sosial berhubungan dengan self-esteem pada remaja (Alfiasari, Latifah, \& Wulandari, 2011), dan self-esteem remaja merupakan salah satu faktor yang berperan dalam menurunkan pengalaman kesepian pada remaja (Zhao, Kong, \& Wang; 2012). 
Secara praktis, penelitian ini menyarankan agar orangtua dan pendidik memerhatikan serta mengajarkan kecerdasan sosial kepada remaja agar remaja tidak mudah mengalami kesepian. Remaja yang cerdas secara sosial akan lebih terampil secara sosial dan mampu memahami keadaan sekitar, sehingga memiliki kualitas pertemanan yang lebih baik dan lebih terlindungi dari kesepian.

Peneliti menyadari bahwa masih terdapat keterbatasan dalam penelitian ini. Oleh karena itu untuk penelitian selanjutnya disarankan untuk menambah jumlah partisipan penelitian agar data yang dihasilkan lebih baik. Selain itu, dapat pula diteliti mengenai hubungan antara kecerdasan sosial remaja dengan kesepian, namun menambahkan lagi variabel harga diri sebagai variabel moderator.

\section{Ucapan Terima Kasih (Acknowledgement)}

Peneliti mengucapkan terima kasih kepada Direktorat Penelitian, Pengembangan, dan Pengabdian Masyarakat Universitas Bunda Mulia yang telah mendanai penelitian ini.

\section{REFERENSI}

Acquah, E.O., Topalli, P., Wilson, M.L., Junttila, N., \& Niemi, P.M. (2016). Adolescent loneliness and social anxiety as predictors of bullying victimisation. International Journal of Adolescence and Youth, 21(3), pp. 320-331.

Agusti, .R.D.C.W., \& Leonardi, T. Hubungan antara kesepian dengan problematic internet use pada mahasiswa. Jurnal Psikologi Klinis dan Kesehatan Mental, 4(1), pp. 9-13.

Alfiasari, Latifah, M., \& Wulandari, A. (2011). Pengasuhan otoriter berpotensi menurunkan kecerdasan sosial, self-esteem, dan prestasi akademik remaja. Jurnal Ilmu Keluarga dan Konsumen, 4(1), h. 46-56.

Baron, R.A. \& Byrne, D. 2005. Psikologi sosial. Jakarta: Erlangga.

Goleman, D. (2006). Social intelligence. New York, NY: Bantam Book.

Gultom, M.S. (2005). Kesepiankah anak remaja kita di rumah?. Diunduh dari http://www.kemsos.go.id/modules.php?name=Content\&pa=showpage\&pid=169.

Hardie, E., (2007). Excessive internet use: The role of personality. Australian Journal of Emerging Technologies and Society, 5(1), pp. 34-47.

Laursen, B., \& Hartl., A.C. (2013). Understanding loneliness during adolescence: Developmental changes that increase the risk of perceived social isolation. Journal of Adolescence, 36(6), pp. 1261-1268.

Mahon, N.E., Yarcheski, A., Yarcheski, T.J., Cannella, B.L., Hanks, M.M. (2006). A metaanalytic study of predictors for loneliness during adolescence. Nursing Research, 55(5), pp. 308-315.

Nurmina. (2008). Peran persahabatan dan harga diri terhadap kesepian pada remaja (Tesis tidak diterbitkan). Universitas Gadjah Mada, Yogyakarta.

Page, R.M. (2006). Hopelessness \& loneliness among suicide attempters in school-based samples of Taiwanese, Philipine \& Thai adolescents. School Psychology International, 7, 583-596.

Papalia, D.E., \& Martorell, G. (2014). Experience human development $\left(13^{\text {th }}\right.$ ed.). New York, NY: McGraw-Hill.

Reis, O., \& Buhl, H. M. (2008). Individuation during adolescence and emerging adulthood-five German studies. International Journal of Behavioral Development, 32(5), pp. 369-371. 
Russell, D.W. (1996). UCLA loneliness scale (version 3): Reliability, validity, and factor structure. Journal of Personality Assessment, 66, h.20-40.

Santrock, J.A. (2005). Adolescence ( $7^{\text {th }}$ ed.). New York, NY: Mc.Graw-Hill.

Silvera, D.H., Martinussen, M., \& Dahl, T.I. (2001). The Troms $\varnothing$ Social Intelligence Scale: A self-report measure of social intelligence. Scandinavian Journal of Psychology, 42, h.313-319.

Tiska, S.Y. (2012). Hubungan antara kesepian dan kebutuhan afiliasi pada remaja akhir yang senang clubbing (Skripsi tidak diterbitkan). Fakultas Psikologi, Universitas Gunadarma, Jakarta.

Triani, A. (2012). Pengaruh persepsi penerimaan teman sebaya terhadap kesepian pada remaja. Jurnal Penelitian dan Pengukuran Psikologi, 1(1), pp.128-134.

Hidayati, N.W. (2016). Hubungan harga diri dan konformitas teman sebaya dengan kenakalan remaja. Jurnal Penelitian Pendidikan Indonesia, 1(2), h.31-36.

Vanhalst, J., Luyckx, K., \& Goossens, L. (2014). Experiencing loneliness in adolescence: A matter of individual characteristics, negative peer experiences, or both? Social Development, 23(1), pp.100-118.

Zhao, J., Kong, F., \& Wang, Y. (2012). Self-esteem and humor style as mediators of the effects of shyness on loneliness among Chinese college students. Personality and Individual Differences, 52, pp.686-690. 